\title{
Mind-Language, the Expanding Heart of Cognition
}

\author{
Jacques Coulardeau \\ AIPL, Association Internationale de Psychomécanique du Langage, Montgeron, France \\ Email: dondaine@orange.fr
}

How to cite this paper: Coulardeau, J. (2018) Mind-Language, the Expanding Heart of Cognition. Open Journal of Social Sciences, 6, 32-47.

https://doi.org/10.4236/jss.2018.66004

Received: November 11, 2017

Accepted: May 20, 2018

Published: May 23, 2018

\begin{abstract}
On the basis of already published research on the phylogeny of language during the emergence of Homo Sapiens starting around 300,000 years ago, and on still-to-be-published research in its final phase on the psychogenesis of language starting in the $24^{\text {th }}$ week of gestation, I will present my work on the central role of two virtual human constructs of man's nervous system and brain confronted to their real environment, both natural and social. These two constructs, the mind and language, are the results of the development of the general pattern-capturing potential of the brain's architecture. The mind and language develop simultaneously, reciprocally and in close coordination transforming the pattern-capturing potential of the brain into the mental and linguistic conceptualizing power of men and women. This long process of development can be captured in six stages: to sense; to perceive; to discriminate (or recognize) patterns; to experiment; to speculate, and to conceptualize spatial items and temporal processes. In psychogenetics, these six stages are essential for education. Lev Vygotsky, among others, has proposed the best approach to this conceptualizing competence in children and young adults, and expanding in our whole life.
\end{abstract}

\section{Keywords}

Mind, Language, Conceptualization, Cognition, Education

\section{Introduction}

First let's refer to already published research [1] [2] [3] about the phylogeny of language within the emergence of Homo Sapiens in Africa and then in connection with the successive migrations out of what is today Black Africa. First to Northern Africa developing first articulation root languages, mainly known as Semitic languages $(\approx 180,000$ years ago). Then to Central Asia and Asia giving 
birth to second articulation languages known as character or isolating languages ( $\approx 110,000$ years ago). Then to the Middle East and Europe first giving rise to the agglutinative third articulation languages $(\approx 75,000$ years ago), and slightly later but to stay for a long period on the Iranian plateau the third articulation languages $(\approx 50,000$ years ago) that will give birth to Indo-European and Indo Aryan languages when the people moved west and east respectively after the Ice Age, to Europe and to the Indian sub-continent ( $\approx 15$ - 14,000 years ago).

To speak of the psychogenesis of language in first-language learners, I am deeply convinced the process a child learns his first language is in many ways parallel or similar to the way Homo Sapiens developed language and languages. Language is a system of systems architecturally constructed with three articulations in order for a speaker to communicate with people within a communicational situation that is forbidding and awe-inspiring to the newborn who only wants to survive in comfort with the help of people he has to progressively capture and mobilize by his calls, crying and later words.

Language leads to full conceptualizing power within fifteen years, making these abstract notions more and more complex. The brain bombarded by sensory impulses processes them to identify and discriminate patterns and it virtually constructs the mind that enables the learner to learn the language/languages spoken around him/her. This language is the second virtual construct of the human subject devised in his/her communicational situation.

There is no cognition possible if these mind and language/languages are not virtually constructed by the brain from its processing all received sensory impulses. Both constantly expand in the child, teenager and adult. They are simultaneously and mutually developing. There is little mind without language and vice versa little language without the mind.

\section{Language before Language}

Starting in the $24^{\text {th }}$ week of pregnancy, a child can hear and it was proved after birth that the child had actually registered some clusters of sounds he had heard from inside his mother. In Roubaix, France maternity in the 1980s, some doctors wired the fetus inside the mother's uterus to record what the child could hear. Everything said by the mother or within one meter of the mother was distinctly heard. After birth, they submitted the newborn to words among which they added the names of the siblings (large families with several grown children). The newborn reacted with his/her eyes to the clusters he/she recognized, he/she had registered in his/her brain. At the top of these clusters were the names of the siblings. The fetus had isolated these clusters and memorized them. Before birth, the brain of the child is already working the way it is going to work systematically all life long.

The brain receives sensory impulses from the various senses and sensors in the body. The highly parallel hierarchical brain processes these impulses (sensations) to turn them into perceptions. Then the brain can capture or isolate pat- 
terns in what it perceives or later on recognize patterns already captured and isolated in what some cerebral machine code. The child's brain works like any animal's brain. Animals recognize us, are able to orient themselves in space, to recognize places. The first stage in three steps:

1) To sense, sensations, nervous impulses going to the brain;

2) To perceive, perceptions, sensations turned compatible with the brain, that the brain can then analyze;

3) To identify/isolate (later recognize) patterns perceptions: anything making items specific and particular. The brain codes and memorizes them in cerebral machine code.

As soon as the baby is born he/she is confronted to the world and human beings moving, speaking and doing many things. At birth the continuous flow from the mother stops and the child starts feeling thirst and hunger, cold and heat, and he/she is going to attach some memorized linguistic clusters to actual referential items. But his/her immediate urgency is to satisfy his/her needs and since he/she is so locked up in his/her impotence he/she expresses his/her needs. $\mathrm{He} / \mathrm{she}$ cries. The first time it is the mark of his being alive outside his/her mother. But the next time the baby expresses a need and he/she discovers that crying is a call, that one of the people around him/her will answer the call and satisfy the need. Within a few hours the baby is able to learn that he/she is in a communicational situation and that his/her calls bring a response.

The baby thus learns

1) he/she has need screating some discomfort;

2) he/she can "call" and someone will respond;

3) he/she has acquired the dynamic of the communicational situation.

This communication is fundamental. The persons taking care of the baby must speak TO the baby, touch the baby to express care, love, emotion, empathy, and most of all establish eye contact as soon as possible, all the time. Eye contact is communication. It is essential for children who may develop some form of autism. These communicational situation and eye contact, when used properly and with intensity and empathy, may help children who may find it difficult to establish contact.

On the basis of this experience the child will learn one or two languages from the very start within just a few months.

\section{Learning the First Language(s)}

The baby cannot speak a word but the mind constructs a matrix of the communicational situation (Figure 1). The baby does not differentiate the relation established by this action of calling, from the caller to the callee, from the theme of this calling, the call itself. Later when the call becomes something else than crying, the child devises a phonetically processed call. This will take time. What is important is that this situation is the matrix of the agentive relation, or an ergative relation. The two may be in discriminate for a long time. They will discri- 
minate from each other when the child learns his/her first language or languages. We should study agentive and ergative structures in a child's language within his/her learning process when from birth the child is confronted to two languages, one agentive, and one ergative. A child confronted to two languages, if clearly determined by the people speaking them and the situations in which each one is spoken(for example one language for use by parents and children within the closed family circle and the other when people from outside intervene, the language of/from the outside society), that child learns both languages equally. What happens when the two languages are different or antagonistic in their levels of articulation and/or syntactic elements?

The agentive relation for food requires the child to differentiate the action from its theme that is called for by the caller (to the callee), then provided by the feeder (to the feedee). The material communicational and caring situation makes the child build in his/her mind the two elements, the relation and its theme, by discriminating them in the symbiotic calling, and this leads to the situational differentiation between the feeding relation and the food theme of this relation (Figure 2).

This existential and purely circumstantial matrix produces in the mind of the child who cannot speak yet the matrix from which the language will be constructed. I give here the agentive relation but the ergative relation-or the passive relation if a language builds its architecture on a basic passive structure-are similar in terms. This graph is a meta-communicational structure. The capture of this relation as agentive, ergative or passive distributes the elements in the linear space of discourse and grants them various markers accordingly (Figure 3 ).

The stress on the agent leads to an agentive relation. The stress on the theme leads to a passive or ergative relation and the stress on the goal (here the beneficiary) leads to a passive or ergative relation. Some languages accept the two passive relations, some only accept one centered on the theme, within the type of relation. In English, we can say "Paul is fed by his mother," "Paul is fed some soup by his mother," "Soup is fed to Paul by his mother." In French, we can say "Paul est nourripar sa mère," and nothing else: three versus one.The verb "donner" has a wider choice. "Le livre a été donné," "Le livre a été donné par Paul," "Le livre a été donné à Pierre," "Le livre a été donné à Pierre par Paul." English has a greater choice. "The book was given," "The book was given by Paul," "The book was given to Peter,"'The book was given to Peter by Paul," "Peter was given the book by Paul," "Peter was given the book."The two passives on the goal of the action are impossible in French: six versus four.

This is not inborn in the child but constructed by the brain bombarded with stimuli, confronted to the communicational situation. It is constructed in the mind and the mind is not an organ but a virtual construct. The child builds his/her mind before he/she starts speaking. The matrices he/she builds in his/her mind are the matrices in which language will be cast later just the same matrices enabled Homo Sapiens to develop articulated language a long time ago.

The child's learning the language or languages he/she is surrounded by is the slow maturation of the body (lowering of the larynx, growing of teeth) and the 


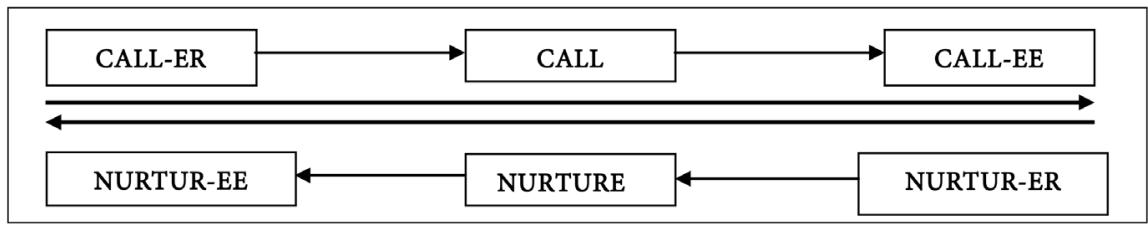

Figure 1. A baby's communicational situation

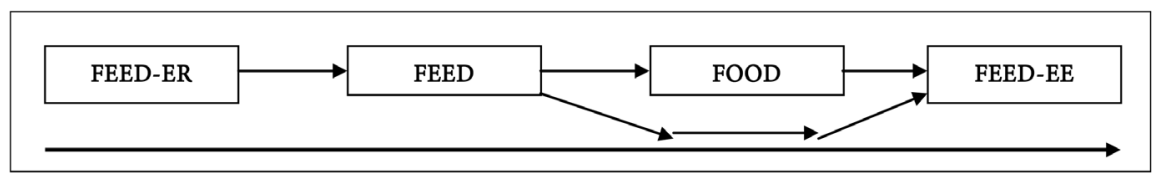

Figure 2. Basic twofold feeding relation.

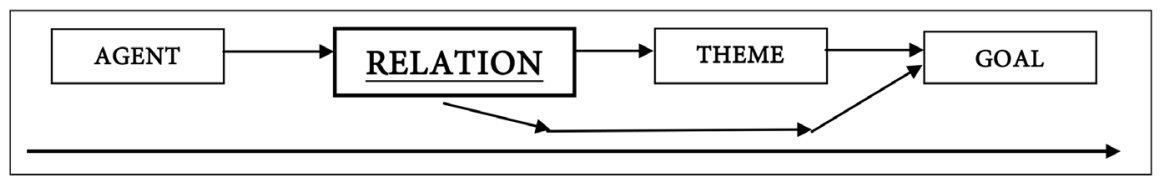

Figure 3. Basic agentive relation.

exploitation of the vocal potential this maturation brings, enabling the construction of the mind and articulatory power.

\section{From Cerebral Code Language to Articulated Language}

This second phase of language learning or constructing only develops in the mind. It is entirely virtual, though the brain is the depositary of it (it safeguards and memorizesit). A brain is a dictionary form without any lexical content at the beginning.

The first triad, to sense-to perceive-to identify, was borrowed from Bertrand Russell's approach of the mind. The second triad I am going to consider is vastly borrowed from Jean Piaget [4] [5] [6] [7], Lev Vygotsky [8] [9] [10] [11] [12], and others specializing in child's cognition, but also from the deeply cognitive and psychogenetic theories of Gustave Guillaume. The supporting theory is cognitive and language is first of all a cognitive tool leading to action, even if it is contemplation.

The first step is "To experiment." Language experiments with the linguistic patterns received from the brain to use them-when the child can of course-to target some objective or some actor to satisfy his/her objective evolving from need to desire. This is true of all human actions. Endowed with some experiential knowledge, a human being experiments with this knowledge to find its characteristics and build its user's guide. For a child learning a language, the first step is the ability to articulate syllables, single or repeated syllables, then words of one syllable or two different syllables. The consonant " $m$ " comes from the child's suction movement of his/her lips when breast-fed by his/her mother or with a bottle. Plosives " $p$ " and " $b$ " are the reverse movement of the lips terminating the suction movement. Dental " $\mathrm{d}$ " and " $\mathrm{t}$ " are more complex since they 
need the growth of teeth to be articulated. Words like "mama," "papa," "baba," "tata," and "dada" and variations are used by the child to designate people around him/her. "Mama" and all other words of this level are used at the first level of "conceptualization" when two or more objects are covered by the same word because they are concomitant now, next to each other when the child uses the word. That's Vygotsky's first level of concepts [8] [9] [10] [11] [12]: regrouping items under one lexical unit because of their proximity when the word is used. This proximity class lasts as long as the proximity is visible to the child. But the repetition of that situation (crèche everyday) may solidify the words beyond plain referential presence and designation, hence as a notion captured in absentia.

If the word is a call, then the child sees if the result corresponds to what he/she has so far understood in that word. If he/she calls "mama" and his/her mother comes the referential value of the word is reinforced. Otherwise, he/she is confused. But this same word covers the need of the child and if it is hunger the food or the feeding will also be "mama." The three may be expressed by one word for some time. A pattern covering a set of elements is captured as one, only later the mind will be able to discriminate patterns in patterns and it will differentiate between "feeder," "feeding process," and "food" along lines that are not the same for all children: it is a personal experience, a personal constructive process. A child who was raised from three months onward in a crèche where he (it was a boy) stayed all day from 7 am to $7 \mathrm{pm}$, used the word "mama" for the ladies taking care of him in that crèche and for his mother when she took care of him. The father suggested to call the mother with a shortening of her name, "Lulu," and the child developed three words for his nurturers: "mama" (crèche personnel), "Lulu" (mother), and "papa" or "dada" (father), the third nurturer who took care of him and brought him to the crèche in the morning and retrieved him in the evening.

The second step is "To speculate." All human beings do this after experimentation, to devise abstract knowledge about the experience and experimentation to guide them in future implementations of this knowledge. The first step of such speculation is the famous two-word sentences. The child must be able to assign order and separate semantic value to the two words. He/she must also assign to the two words the embryo of a syntactic value.

The child must learn a word for the feeding process and the food, at first indiscriminate. His/her first sentence is then a call to his/her nurturer for "feeding-food." If the nurturer responds properly, the child's speculation is reinforced and he/she can move to another level of experimentation/speculation that brings the differentiation between the process of feeding and the food, with a special word for that food. The child might stay for a while within the two-word sentence phase with "mama-feed" and "mama-food," these sentences being theoretical because it is always a personal and individual process for each child. If the first food the child identifies is "rice" he/she will produce theoretical sentences like "mama-feed" and "mama-rice."That could explain the use of generic objects with some action like in Chinese, but also within word composition like in Eng- 
lish with verbs including a generic object as a first element like in "proof-read," "book-read," "lip-read," "mind-read." These compound verbs with generic objects are common in their gerund or present participle forms: "He is constantly mindreading (people)," corresponding to "He is constantly reading minds," or "He is constantly reading the minds of people," still generic but becoming specific in "He is constantly reading the mind of his wife."

In this phase, the child is projecting the communicational situation he/she has experienced for a year or more, and on which he/she has experimented all along, casting what he/she tries to express in the matrix of this communicational situation. This communicational situation and its matrix become the matrix of the syntactic construction of the language(s) the child is learning. The child is not able to produce a syntactically constructed sentence for quite a while. He/she has to capture the difference between space leading to spatial items and time leading to temporal items. These two categories are fundamental, probably universal. In some languages the temporal items are invariable but time is understood and expressed. Space may not be expressed per se but space is understood and expressed. Linguists have a tendency to project onto all languages the particular forms these two categories take in (most) third articulation (agglutinative and synthetic-analytical) languages, nouns and verbs. We have to consider more abstract categories: space and time. Space leads to some static elements defined by their place. Time leads to dynamic elements that can move from one state or place to another, which always takes some operational time. This temporal side of the world is mentally and linguistically built on the model of the spatial side of things.

Some languages, like the Salishan languages in Canada and the USA, are debated because they do not seem to differentiate between noun and verb categories. Their roots seem to be unmarked and it is a specific mark added to these roots that make them "verbal" or "nominal." But it would be more interesting to see if words like "Pux" and "sbiaw" in "PuX ti sbiaw" "the coyote runs") are "verbal" or "nominal" perse or if it is the "specifier" " $t i$ " that establishes a predicative relation between the two beyond the fact that both words can be understood as both spatial hence "nominal" ("he who goes" hence "goer," and "coyote") as well as temporal hence "verbal" ("go" and "be a coyote"). One expresses a movement, hence both space and time, the other expresses an essence, hence static. The polemic raged in older decades but if we state-from pure observation based on the consciousness of the speakers-theword order is "verb" first then it is clear langue does not have the categories of "nouns" and "verbs" but discourse producing the utterance works on the differentiation between spatial-temporal and spatial-static.

We have exactly the same problem with all root languages. The roots, the only langue elements, are neither nouns nor verbs and it is only discourse dictating the morphology and syntax that turns " $k$ tb" into a verb or a noun in Arabic or Hebrew. For the Arabic verb, we have on initiation sites (most translations are wrong and Indo-European centered): Kataba, "he wrote" (masculine); katabat, "she wrote" (feminine); katabtu, "I wrote" (feminine and masculine). For the 
noun we have: kitāb, "book"; kutub, "books" (plural); kutayyib, "booklet" (diminutive); kitābat, "writing"; kātib, "writer" (masculine); kātibat, "writer" (feminine). The root is " $k \mathrm{tb}$ " and then you have a discursive stem for the verb, "katab," and two for the noun, "kitāb," for the object, including the action, and "kātib" for the agent. Linguists trained in third articulation languages project their third articulation categories onto all other languages: verbs and nouns everywhere, though in English the distinction that used to exist is disappearing with many words like "work" and it is always possible to use any discursive unit as a verb or a noun, taking a third articulation discursive utterance and casting it back into the spatial hence nominal or temporal hence verbal categories of the second articulation.:"Don't mother-fucker-sir me please!" (negative imperative verb); "He is the worst mother-fucker-sir professor I know!" (superlative + compound of a nominalized discursive utterance and another noun); "Paul is always mother-fucker-sirring me in spite of my protest!" (present progressive verb hence using a present participle).

The third step is "To conceptualize."The linguistic items, words or operations or functions, are captured and defined abstractly. But yet there are different levels of conceptualization. The simple word "dog," often of a smaller size is a pet for an older person, but an assistant of a bigger size for a hunter or a shepherd, and the same dog for a biologist will be his/her scientific definition. A veterinarian if the dog is rabid, will only put the dog to sleep and discard the body. The pet owner will cry eventually and verify his/her vaccination.

This second triad can only start when a child is able to produce two-word sentences, and it leads to abstract conceptualization around twelve years of age that comes to full development only around eighteen and it is still growing in adult age, though probably at a slower rate for most people.

\section{Vygotsky and Conceptualization}

First, the child goes through a phase that builds unorganized congeries or heaps of objects in three steps. The three steps state that the concerned objects are in a way or another present when gathered into heaps, hence the rule is proximity, both temporal and spatial. First heaps of objects are brought together on a simple trial and failure basis, hence on a simple proximity. Pure experiential trials and failures. Then the proximity is positioned in space, some kind of spatial vision with things positioned in it. The third heap is endowed with a unique signification. Then a word becomes necessary to give the heap a unifying label.

The second stage is complexes. The child sees bonds that actually exist among the concerned objects, a color, a shape, a texture, etc. First, associative complexes, the continuation of the previous stage. Next collective complexes or complex-collections. All objects have some common trait but the collection cannot contain two identical objects. This is a constructive process. The next step is chain complexes: the characteristic is transferred from one object to the next in a chain of objects. The transferred element can change along the chain: red square to red round, round yellow to round blue, blue round to blue trian- 
gle, etc. That leads to a diffuse complex in which the common feature in all items is fuzzy: it is common but not quite clearly discriminated. It leads to the step of pseudo concepts. Externally they are concepts clearly "defined" by some element, but internally they are objects that may have little to do with one another. The child might have well discriminated a certain color or shape and he/she may bring together objects of the same color but some are living objects, others plain static objects, etc. A cat, a dog or a bird are all moving. A fly and a bird both fly.

Vygotsky [8] [9] [10] [11] [12] states we have to introduce some historical perspective, some genetic approach in our experimental analysis. History as the historical period when a child lives with its environment and its culture: children imitate adults and Vygotsky did not know about mirror neurons. These mirror neurons are essential. A child can capture every meaningful element in the behavior or language of an adult, even before he/she is able to speak. History is also the personal history of the child in his environment. The genetic element is the psychogenesis of language and concepts, though some phylogenetic dimension could be seen too in the fact everything that surrounds the child has a phylogenetic history. We must also keep in mind language is a communicational medium with a rich and long phylogenetic history.

With pseudo concepts the child starts developing the decomposition of objects into characteristics, the analysis of these features and the abstraction of them by considering the separate features each one in itself and all together. To abstract something, you can only do it by discriminating this element from the simultaneous abstractions of other elements. Then objects are classified as, first, potential concepts on the basis of maximal resemblance, a maximal number of common features. These pseudo concepts are pre-intellectual, defined by a practical reference to a precise circle of objects, within discriminating abstraction. These pseudo-concepts are not based on what the objects can do but on what the child can do with these objects.

A young teenager, within a concrete, meaningful and motivating situation, brings together the previous representations and complexifies the relations between the objects within wider sets. The really new element is that of judgment. $\mathrm{He}$ is actually always assessing the utility for him to know this or that, to generalize this or that. Judgment is mostly self-oriented and self-centered.

Around twelve the child enters the intellectual age with two roots: a widening and deepening of the child's ability to build complexes and reach potential concepts. Vygotsky opposes in nature, genesis and value two types of concepts: spontaneous everyday concepts built from direct existential experience, and non-spontaneous scientific concepts built from education. Both exist side by side and can overlap: scientific concepts are the result of the child's education which is existential and experiential It reinforces previous relations within the family circle with transference phenomena. At the same time, it may be captured as either complementary, alternative or even antagonistic. This intellectual con- 
struction of scientific concepts at school may become a refuge from the family circle, an antagonistic experience the teenager, can peacefully assume or more or less aggressively express against people in his immediate family circle.

The first step in this genesis of scientific concepts happens in primary school and it can easily be amplified by school work but for Vygotsky, you cannot force someone to learn a concept and make it operational. It has to correspond to a level of maturation. This means it is better to lead children towards discovering these concepts with and in their own activities, like reading, writing and arithmetic that enable a child to learn how to recognize-conceptualize the letters or characters of his/her language, motivated by the curiosity about what is written on the page. He/she will simultaneously learn how to write, to transfer the recognition of the letters and their association to sounds to hand movements and special tools to write, pen, paper, etc.

The second step is in junior high school, at the beginning of adolescence. The teenager develops, simultaneously and continuously, concepts and word meanings in one single movement. Learning is as a process that constructs both the conceptual lexicon and the mind of learners.

The third step is more heuristic and has to do with the method. The school system imposes or proposes to discover new concepts by constructing them with a method mostly based on deduction, induction and cause-effect abstraction. It is best if this learning is based on experience and experimentation. Motivation is the most important element in this perspective: all learning has to be self-oriented and self-motivated.

The learning/discovery of scientific concepts builds up ability in the mind that uses the brain's structure and functioning to construct what Vygotsky calls a "system" and it is more than ONE system but it is ONE system of MANY systems. This hierarchy of systems or systemic architectures and abilities takes time and is NEVER finished, hence cannot be brought to a terminal state.

\section{Visual Summary}

Right at the beginning of the genetic process, you have to take into account what the heritage of the child is, in fact, the outside world and the phylogenetic process that produced the human child he is. This outside world is hierarchical by architecture and in this set of hierarchies, the senses are central since they are the direct link between the individual child, and the outside world he/she experiences existentially with the main need at birth: the need to adapt in order to survive (Figure 4).

The Senses' Hierarchy is the main interface between the child and the world. This interface is in direct connection with the brain and the cortex through the basic senses and the nervous system. The five senses are well known though we have to add to these all the sensors in the body that inform the brain of the situation, state and physiological needs of this very body, like hunger, thirst, etc. But we will only consider the five basic senses (Figure 5). 


\begin{tabular}{|llllll|}
\hline \multicolumn{5}{|c|}{ NATURAL EVOLUTION + HUMAN EVOLUTION } \\
\hline \hline The world's & Life's & The body's & The senses' & The brain's & The cortex's \\
Hierarchy & Hierarchy & Hierarchy & Hierarchy & Hierarchy & Hierarchy \\
\hline
\end{tabular}

Figure 4. Humans confronted to nature.

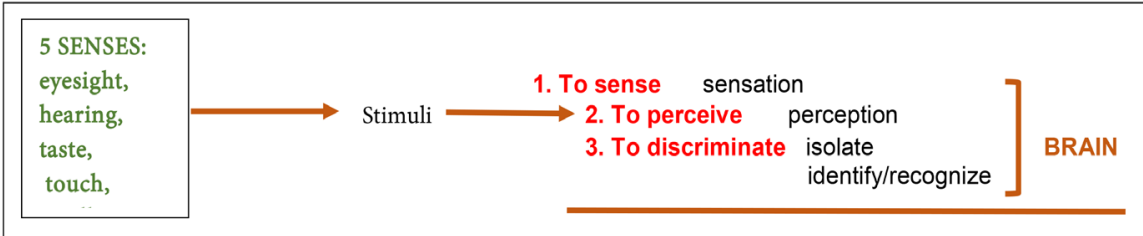

Figure 5. From the senses to the brain.

On the basis of this brain and central nervous system the dual construct of MIND and LANGUAGE develops. This complex virtual construct rooted in the brain must be seen as a constantly evolving, developing dual entity (Figure 6).

That's this mind that will produce, construct, generate the Mental Constructs and Conceptual Notions of abstract thinking as well as the Linguistic Items based on the duality Signifying/Signified(Ferdinand de Saussure) or Content-Form/Meaning (Gustave Guillaume) in three successive operations (Figure 7):

The mind is in many ways a circular engine that constantly produces Mental Constructs and Conceptual notions on one hand, and on the other hand Linguistic Items characterized as connecting a Signifying Form and a Signified Meaning or Content. The Mental Items via the three operations we have identified, generate the need for new or updated Linguistic Items, and at the same time, simultaneously and reciprocally, the new or updated Linguistic Items produce through and in the mind itself new or updated Mental Items that will immediately be experimented upon, speculated about and conceptualized to be finally fed to the linguistic side of things to create new Linguistic Items or update older ones. That circularity is essential to understand the cognitive process of learning. The new knowledge is not part of the Mental Constructs and Conceptual Notions of the mind and the three operations will enable the assimilation of the necessary words or phrases or concepts to cope with this new knowledge but the cognitive process is only finished when this updating or assimilation process is transferred to the Mental side of things. Here is the necessity for this new knowledge to have roots in the Mental Constructs and Conceptual Notions to be learnable, integratable. That's Vygotsky's [8] [9] [10] [11] [12] zone of proximal development. More in a moment (Figure 8).

And it is this full vision of the MIND-LANGUAGE that produces all mental creations and constructions of humanity, particularly the three below supporting human experience in three dimensions (Figure 9).

\section{The Zone of Proximal Development}

This mental approach of language and cognition opens on an essential concept 
EXISTENTIAL EXPERIENTIAL

CIRCUMSTANTIAL SITUATIONAL NATURAL

M I N D - L A N G U A G E

Meta-sense Medium

CONDITIONS

RECIPROCAL SIMULTANEOUS CONSTRUCTS

MIRROR NEURONS AND EMPATHY

EXTRFME FRAILTY OF THE SPECIES

EXTREME DEPENDENCE OF THE YOUNG

SOCIAL ORGANIZATION:

DIVISION OF LABOR

LANGUAG

Figure 6. The Mind and Language.

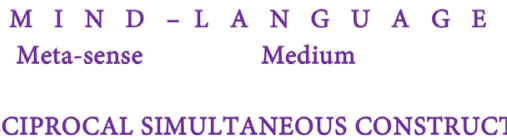

4. To experiment

5. To speculate

MIND

RECIPROCAL SIMULTANEOUS CONSTRUCTS

6. To conceptualize

Figure 7. From identified patterns to concepts.

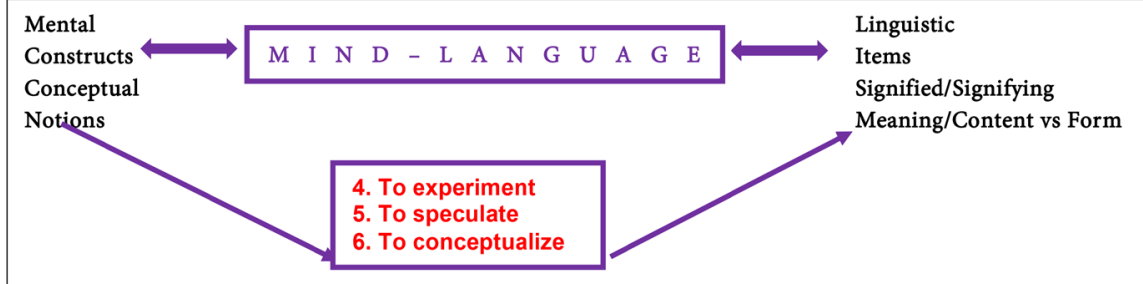

Figure 8. The circularity of Mind-Language.

\begin{tabular}{|ll}
$\begin{array}{l}\text { Human action } \\
\text { And behavior } \\
\text { Passionate empathy }\end{array}$ & $\begin{array}{l}\text { Hallucination/vision } \\
\text { Invention/art } \\
\text { Irrational } \\
\text { Imagination }\end{array}$
\end{tabular}

Figure 9. The source of all cognition and creation.

that Vygotsky does not share with Jean Piaget [4] [5] [6] [7]. Piaget always defended that maturation was natural, going along with the growth of the body, and the child was only capable of doing what his or her maturation enabled him or her to do. This domination of mental maturation by physical and physiological maturation justified Chomsky's consideration that language was a black box in the brain that contained Universal Grammar in all its operations and complexity only needing to be activated by gene-controlled maturation and social, cultural or educational prompting. For Piaget and Chomsky cognition is thus natural, meaning inborn in its very genetic development. The environment is at best a prompter and at worst purely circumstantial if not negligible.

Vygotsky [8] [9] [10] [11] [12] defends a really didactic, pedagogical, in one word, cognitive approach. You cannot ask a child who has not constructed a certain level of abstract conceptualization along a phylogenic line of mental de- 
velopment, and the phylogenic dimension of his development is essential, to learn something that has no roots in what the child already knows, but at the same time if you follow this phylogenic development you should always propose the child an activity that will activate the next phase of his/her development. Vygotsky refuses to let children only do what they already know how to do and he advocates to be just one small step ahead in what he calls the "zone of proximal development." In his standard approach, it is more conceived as a limit than as a potential. His concept of mental age is disconnected from the real age of the child because it is the ability to solve some problems by him/herself. But each child is unique and Vygotsky does not insist enough on the necessity for the new knowledge to have roots in the already acquired knowledge, which makes the task of learning more complex since rote learning is out: it must be integrated into old knowledge that must be restructured accordingly. And yet Vygotsky is totally aware that you have to prompt learners into discovering new concepts or knowledge: "With assistance, every child can do more than he can by himself-though only within the limits set by the state of his development." (1962, p. 103)

This zone of proximal development must be used in school education. Since the mental maturation of a child is phylogenetically governed and we can through observation know the successive phases of this phylogenetic development, we can always propose children to learn something they do not know or control yet, but always starting from what they already know or control. A simple example in the field of language learning can make this clear. A child born in a bilingual family, if the two languages are clearly defined, by the age of four or five - may be even six if he/she is not attending school regularly in these 4 to 6 years - this child will have a slight deficit in lexicon in each language as compared with monolingual children. But altogether the lexicons of his/her two languages will exceed the average lexicon of a monolingual child in any of the two languages. This deficit will be caught up by the age of seven in the two languages.

To give a second example I would say that the earlier you introduce the full interrogation and negation in English using the auxiliary "do," the better. All other strategies like using the progressive form for full verbs, hence the auxiliary "be," or the modal "can" as an auxiliary will strengthen in the learner forms that are not fundamental phylogenetically in English, and this may even reinforce the forms of the first language of the learner that may only use an inversion verb-subject for the interrogative form. The progressive form developed late in English and it is a lot more complicated to understand for children who do not have that kind of auxiliary-using analytical verbal construction in their mother tongues, and the use of modals as auxiliaries to prevent the use of "do" is dangerous because it may weaken if not erase the meaning of these modals. That is how you can see the zone of proximal development is not a handicap or a limitation. It is a potential for further development. A child will not learn how to multiply naturally because it is not part of his nature, but he will learn it from activi- 
ties that will require him to learn it, though he will not be able to understand the operation before the age of seven or eight. It would be vain to start with multiplication tables if the child does not understand adding and subtracting, not to mention dividing which will have to come last.

And imagine the next step: proportions or ratios. Starting with a rectangle whose width is 5 inches and whose length is 12 inches what will the length of the rectangle be if we increase the width to 9 inches and if we keep the same proportion it has with the length in the initial rectangle? You need to divide 12 by 5 and then multiply the result by 9 and the length becomes 21.6 inches. This conservation of a proportion or ratio between two or more dimensions when one is changed is a complex operation that requires a lot of training but only when the four basic operations are assimilated. A great number of Romanesque and Medieval buildings and artifacts like churches, water troughs, tombstones were built integrating one proportion number, the Golden Ratio (1.6180...).We are dealing here with a fundamental phylogenic dimension of humanity.

All that is contained in Vygotsky and he worked at a time when mass media were not what they are today. Just imagine a child with the Down Syndrome typing his name on a computer keyboard to be able to access the games he likes on the machine. I have seen that in an educational day-institution for such children, and not recently since I saw it in the early 1990s. You can develop skills in all children, though probably not the same and at the same level for all. You can cope with such facts and situations only if you consider the mind as a construct of the brain and the fact that this mind has its own logic and dynamic for each individual. We have to build a cognitive approach to the world that enables each child or individual to fully use their mind and actual mental capabilities. Any uniform ready-to-use pedagogy that fits all is just vain and it will frustrate those who will be out of the scope of this pedagogy, be they under or over the mental level required to develop the targeted skills.

\section{Conclusions}

As for cognition, it is important to state that a child is born with elements, sound clusters for example, that were acquired, registered and saved before his birth, in the last third or so of the pregnancy, maybe earlier. But this acquired knowledge has to be restructured at once after birth to attach to it a signified referential meaning since what was registered was only a signifying form without a referential meaning. This is the basic process of cognition. A child is confronted with new knowledge. This new knowledge is put in relation with the knowledge the child has already saved. If there is a possible connection it will be integrated into a heap of objects or later on, progressively into a conceptual system. If it has no relation whatsoever there is a fair chance that this new knowledge will not be integrated. One relation is motivation after a certain age, particularly after puberty, but children under 12 can be motivated to act and learn. This motivation enables the child to integrate the new knowledge in what he/she already knows, or in a 
new system that will be connected to older systems later. Knowledge is ONE hierarchical system of MANY systems, just like language. New knowledge requires the child to restructure his/her ONE hierarchical system of systems by integrating a new system or integrating new knowledge in already existing systems. This is essential for any pedagogical work. To teach classical culture requires some kind of connection with the students who have no knowledge of it. This could be motivation but it would have to be prompted and nurtured by the teacher. If no motivation and/or connection with the student exists, the student is not able to receive the new knowledge properly or at all.

The second dimension is mentalism. By mentalism I mean the reference to Buddhist "citta" understood as a meta-sense. An individual consciously or unconsciously uses his mind to cope with the world. This mind is a potential of the brain but it has to be constructed through experience in real contact with the world. This mind has to be constructed all life long and the main tool of this construction is language which itself is a construct in the mind. Some children learn more when actually doing some physical activity, and yet the child has only learned something if he has built a representation of the action in his mind that either makes him able to demonstrate the action or to explain with words what the action is. Very often the demonstration is accompanied by some deictic language like "You do this, then you do that, then you press this button and you choose that task, etc." This deictic language is very common among people working on computers at a lower or intermediate level. But these people could, if required, write down or explain the procedure on the telephone and then they would have to specify every action and they should be able to do it. This is the mentalism I am speaking of. The mind and/or language are the core and the tool of any learning procedure, even when the learner is unconscious of it because we are so used to using our mind and language that it becomes customary, hence at best subconscious, at worst unconscious, but it works just the same.

When you bring together those two dimensions you can devise a method to amplify the learning process. This method is rather simple: make the learner think about what he has learned at the end of the day, at the end of a lesson, at the end of a search for knowledge. This summarizing of the day's work enables the learner to reinforce the knowledge he has encountered and assimilated. At a more advanced level, it is important for the learner to have a plan before starting that provides some guidelines in the search he/she is entering. A school schedule is such a "plan" since it provides the student with a daily learning frame. But in life it is the same and everyday you have to "know" what you intend to do, what you have to do, what you hope to do, and at the end of the day or the week you have to summarize the day or the week and see what has been done and what still has to be done. That's the power of the model I propose. It is the same for all children or learners but it varies in implementation from one child to the next, from one learner to the next. Some people might never like Shakespeare, until one day they are asked to act one scene and they accept to try, or until one day 
they have the opportunity to see a rehearsal. Then Shakespeare can penetrate their mental world, even if they have to rap the text on some rap music.

\section{References}

[1] Coulardeau, J. and Eve, I. (2016) The Indian Ocean from Admiral Zheng He to Hub And Spoke Container Maritime Commerce. Co-Author, Editions La Dondaine, Amazon Kindle, ASIN: B01AY2H0JC.

[2] Coulardeau, J. (2017) Freedom of Expression and Copyright (1100-2016), The Foundations of All Liberties. Editions La Dondaine, Amazon Kindle ASIN: B06XNJZ4W6, Research, 210

[3] Coulardeau, J. and Eve, I., (2017) Cro-Magnon's Language, First Part. Editions La Dondaine, Amazon Kindle, ASIN: B074DXJM5C, 760.

[4] Piaget, J. (1975) L'équilibration des structures cognitives: problème central du développement. PUF, Paris.

[5] Piaget, J. (1976) Le comportement, moteur de l'évolution. Éditions du seuil, Paris.

[6] Piaget, J. (1988) De la pédagogie. Éditions Odile Jacob, Paris.

[7] Piaget, J. (1990) Morphismes et catégories: comparer et transformer. In: Henriques, G., Ascher, E. and Coll, Eds., Neuchâtel, Delachaux et Niestlé.

[8] Vygotsky, L.S., (1934) Thought and Language.

[9] Vygotsky, L.S. (1962) Thought and Language. The MIT Press, Cambridge.

[10] Vygotsky, L.S. (1978) Mind in Society: The Development of Higher Psychological Processes.

[11] Vygotsky, L.S. (1985) Pensée et Langage. Translation Sève, F., Messidor, Éditions Sociales, Paris.

[12] Vygotsky, L.S. (1987) The Collected Works of Vygotsky, L.S. 